Max-Planck-Institut für demografische Forschung

Max Planck Institute for Demographic Research

Konrad-Zuse-Strasse 1 - D-18057 Rostock - GERMANY

Tel +49 (0) 3812081 - 0; Fax +49 (0) 3812081 - 202;

http://www.demogr.mpg.de

MPIDR WORKING PAPER WP 2012-015

MARCH 2012

\title{
Measuring the balance of government \\ intervention on forward and backward \\ family transfers using NTA estimates: \\ The modified Lee Arrows
}

\author{
Concepció Patxot \\ Elisenda Renteria \\ Miguel Sánchez Romero (msanchez@demogr.mpg.de) \\ Guadalupe Souto
}

This working paper has been approved for release by: Michaela Kreyenfeld (kreyenfeld@demogr.mpg.de), Deputy Head of the Laboratory of Economic and Social Demography.

(c) Copyright is held by the authors.

Working papers of the Max Planck Institute for Demographic Research receive only limited review. Views or opinions expressed in working papers are attributable to the authors and do not necessarily reflect those of the Institute. 


\title{
Measuring the balance of government intervention on forward and backward family transfers using NTA estimates: The modified Lee Arrows
}

\author{
Concepció Patxot ${ }^{(1)}$ \\ Elisenda Renteria ${ }^{(2)}$ \\ Miguel Sánchez Romero ${ }^{(3)}$ \\ Guadalupe Souto ${ }^{(4)}$
}

(1) CAEPS-UB (Centre de Anàlisi Econòmica i de les polítiques Socials - Universitat de Barcelona) and Instituto de Estudios Fiscales (Spain)

(2) CAEPS-UB (Centre de Anàlisi Econòmica i de les polítiques Socials - Universitat de Barcelona)

(3) Max Planck Institute for Demographic Research (Germany)

(4) Departamento de Economía Aplicada, Universidad Autónoma de Barcelona (Spain)

\begin{abstract}
In this paper we propose a way to measure the degree of government intervention on forward from parents to children- and backward -from adult children to elderly parents- intergenerational family transfers (IFT). We carry out a discussion about the possibility of using Generational Accounts (GA) and National Transfer Accounts (NTA) methodologies to generate indicators that could measure government intervention on both sides of IFT. As a result, we propose a modification of arrow diagrams used by Lee (1994b). An illustration of the results in the Spanish case indicates that the degree of government intervention on backward IFT is above that on forward IFT. This could be one of the main reasons to explain the Spanish low fertility rate.
\end{abstract}

Keywords: National Transfers Accounts, Generational Accounting, Fiscal policy, Spain, Population Ageing

JEL: H68, H53, J180

\footnotetext{
Abbreviations: PAYG, pay-as-you-go; NTA, National Transfers Accounts; GA, Generational Accounts; IFT, Intra Family transfers; OLG, Over Lapping Generation; LCD, Life Cycle Deficit; TG, Public Transfers; TF, Private Transfers; ABR, Asset Based Reallocations; SNA, System of National Accounts; GDP, Gross Domestic Product; PAYG, pay-as-you-go.
} 


\section{Introduction}

In most industrialized countries, the ageing process poses a real threat to the sustainability of one of the greatest social achievements of the past century, the welfare state. Besides the traditional constraints on any sound public policy (for instance, instituting tax schedules that are as neutral as possible) a new difficulty emerges, namely the fact that it implies intertemporal movement of government funds.

The reason is merely the fact that most of the social programs (pensions, health care, education, etc.) interfere in both forward and backward intergenerational transfers (from parents to their offspring or vice versa), being affected by demographic changes. By adopting this role, the government might also need to accumulate funds, as agents do along their life cycle. This indeed adds constraints on public finance functioning which entails both intra and intergenerational redistribution. As pointed out by Cigno and Luporini (2006), the need for government intervention on intergenerational family transfers (IFT) remains an unanswered question in the literature.

The most outstanding example turns out to be the public retirement pension system ${ }^{1}$. Public pension systems are, usually, explicitly based on pay-as-you-go (henceforth, $P A Y G$ ) financing, replacing backward family transfers. However its basic parameters do not depend on demographic evolution. This is clearly an embedded contradiction and this is the reason for the future expected crises of the pensions system. There is a wide literature on the effects of ageing on the sustainability of pensions systems both on pure theoretical issues and on applied models ${ }^{2}$. Most of the latter are designed to obtain measures of the sustainability of the system in the face of demographic ageing.

\footnotetext{
${ }^{1}$ The rest of contributory pensions are also affected by demographic changes but to a lesser extent, depending on the age of recipients. Widowhood and family pensions evolve in line with retirement pensions while orphan's pensions, despite implying substitution of forward intrafamily transfers, remain stable or decrease given that they are mainly received by children.

${ }^{2}$ While the theoretical tool at work is the overlapping generations model, the applied works tend to deviate from it to some extent. Along with large-scale applied general equilibrium overlapping generations models we find microsimulation models, which must necessarily incorporate a simulation module of the main macroeconomic aggregates and the productivity level. Additionally, the so-called aggregate accounting models, which are traditionally designed according to the available statistics and the legal framework in each country, have been evolving
} 
Nevertheless, it is usually forgotten that the retirement pension system is only one of the ways in which the government intervenes in IFT, transfers to children being ignored. This is not surprising, as a thorough analysis of this issue would be extremely intensive both in terms of data needs and of theoretical analysis -the latter being especially complex.

The aim of this paper is to contribute to the debate on the role of intergenerational transfers from the empirical perspective. In particular it aims to discuss the possibility of measuring the extent to which the government intervention on both sides of IFT is balanced. To that purpose we discuss the possibilities of using

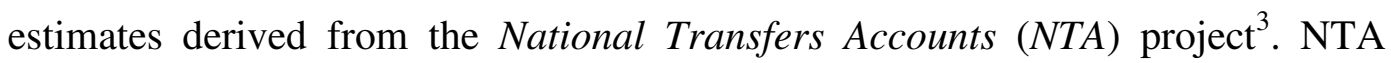
aims to measure the flow of resources that move across age groups by means of transfers -public or private- or the asset market. In particular, starting from the National Accounts and combining it with micro data sets, an age profile is obtained for the so-called life cycle deficit $(L C D)$-consumption minus labour income. Similarly, age profiles for net public and private transfers and for asset income are obtained. As a result one can observe how life cycle deficit (or surplus) is financed through (or finances) the asset market or by means of public and private transfers.

Starting from these profiles and following the logic of arrow diagrams in Lee (1994b), an indicator of the size and direction of intergenerational transfers is proposed. In particular, the profiles are transformed into an arrow that goes from the average payer or producer to the average recipient or consumer, the width of the arrow being the amount of resources transferred. Going a step forward we decompose these arrows in two pieces in order to measure the extent to which government intervention is balanced on both sides of the dependent life.

steadily. They have come to include a greater level of detail and heterogeneity, which makes them resemble non-behavioural dynamic microsimulation models. See Jimeno et al. (2008) for a general survey and Bonin (2001) and Bonin and Patxot (2005) for a survey focused on Generational Accounting and related techniques.

${ }^{3}$ Lee and Mason (2011). See www.ntaccounts.org for details on the NTA Project that groups researchers from more than 30 countries worldwide. 
The paper is organized as follows. Section 2 gives a panoramic view of the issues affecting the role of government intervention on intergenerational transfers, highlighting the difficulties in developing a comprehensive theory on the need for government intervention on intergenerational transfers. Section 3 is devoted to methodology. First, it explains briefly National Transfer Accounts (NTA) and Generational Accounting (GA), a quite complementary and well-known applied technique. Second, it discusses how NTA estimates can be used to obtain balance indicators. Section 4 presents an illustration in the Spanish case of some standard results derived in NTA (4.1) and shows the proposed balance indicators derived using both GA (4.2) and NTA (4.3), the latter containing a modification of the arrow indicators proposed by Lee (1994b). Finally, section 5 gives some final remarks regarding future research.

\section{Intergenerational Intrafamily Transfers: selective overview.}

Table 1 gives a panoramic view of the issues involved in the family transfers to the elderly and to the young, together with some social changes affecting them in present-day developed countries ${ }^{4}$. As a preliminary qualification, it is worth considering that the dependent periods at the beginning and at the end of life differ in many ways. First, having children is, to some extent, a decision (a bilateral one), as not everybody has children, while everybody has a substantial probability of getting old, and hence being a transfer receiver. This gives rise to an almost unexplored redistribution issue. For the economy as a whole, the main asymmetry between the two dependent sides of human life is that giving birth to a child ensures the continuation of the economy and the society and implies a special kind of resource accumulation. Second, leaving aside the strict health care service, the service "care" - also quite unexplored in economic analysis - seems to be, by far, less substitutable by the market during childhood. Third, in general,

\footnotetext{
${ }^{4}$ Note that before the government started intervening in IFT, the extended family was doing the job on both sides. And the financing device was a private PAYG, except for some families who could rely on land rents or who could save and accumulate resources on an incipient capital market.
} 
the possibility of using the market as a financing device is quite limited during youth due to liquidity constraints.

The adequate theoretical tool to approach the need for government intervention on family transfers would be the overlapping generations model (OLG). However, note that it should include all kinds of public transfers and also private transfers arising from the motives detailed in the second column in Table 1. In particular, both backward and forward altruism or, alternatively, the exchange motive or any kind of social contract, should be present. Family transfers would then compete with the other two possible resource allocation devices: market and government. Furthermore, ideally allowing for endogenous fertility would also be a necessary requirement as long as government intervention on IFT might affect the fertility decision. There is a growing literature on the interaction between fertility, growth and intergenerational transfers, though in each case it focuses on the convenience of one particular social program in a simplified setting ${ }^{5}$.

The last column on the first part of Table 1 lists some positive or negative reasons for policy intervention on both sides of family transfers, which differ due to the reasons mentioned above. Being focused on representative agents of each generation, we do not pay special attention to intragenerational redistribution and insurance, which are, to some extent, mixed with other policy objectives, in most social programs ${ }^{6}$. Regarding transfers to the elderly, the possibility of myopic agents under-saving for retirement is often indicated as a reason for a public pension system. Similarly, this social program and the long-term care programs can also be considered as an insurance device ${ }^{7}$. Interestingly, a potential effect of the public pensions system is an external effect reducing fertility, accelerating population ageing and reinforcing the demographic transition experienced in most developed countries from the second half of the last century ${ }^{8}$. Finally, the risk of

\footnotetext{
${ }^{5}$ On the one hand, see Rangel (2003) for an interesting attempt to deal with forward and backward transfers at the same time, in an exogenous growth and fertility setting. On the other hand, see Galor and Weil (2000) for a comprehensive treatment of endogenous fertility in an endogenous growth setting.

${ }^{6}$ Clearly redistribution is a relevant reason in some policies like education, to ensure equal opportunities.

${ }^{7}$ See Sinn (2004) and Crèmer et al. (2006) who consider the pensions system as an insurance device against infertility.

${ }^{8}$ See, for example, Cigno (1993), Zhang and Nishimura (1993) and Wigger (1999).
} 
uninsurable catastrophic illness is often mentioned as a reason for long-term care insurance. Regarding transfers to the young, the positive external effects of education on growth are a clear reason to finance education, which also has positive effects on intergenerational mobility.

The second part of Table 1 mentions some relevant issues that affect the configuration of transfers and the possibility of substituting them by market and public transfers - and hence the need for government intervention: the change in the length of the productive period due to the increase in life expectancy, and the structural change in female participation. Finally, to complete this picture, note that public transfers tend to be financed through a kind of explicit PAYG system as in the retirement pension systems - or an implicit PAYG system, helped, to some extent, by raising public $\mathrm{debt}^{9}$. On the contrary, private transfers are nowadays "explicitly funded" to some extent, in the sense that the household head tends to take it into account in their personal savings plan, except if myopia arises.

Not surprisingly, the complex picture shown in Table 1 has not yet been fully incorporated into a comprehensive OLG model accounting for all the possible transfers that considers all the key endogenous variables. Nevertheless, it is interesting to look at some of the predictions of the standard, non-altruistic, OLG model. The latter already needs some modification in order to approach the issue we are tackling in the simplest way. Indeed, not only were there no inter nor intrafamily transfers - no sign of altruism according to individualistic methodology - but also it considered exogenous freely-raised children. Despite its simplicity this model was useful for its aim: endogenize savings, -i.e. the financing of the elderly dependent period-completely ignoring the other side of the dependent life and the links between parents and grandparents ${ }^{10}$.

\footnotetext{
${ }^{9}$ Note that the need for a public retirement pension system does not imply that it should be financed on a PAYG basis.

${ }^{10}$ For an interesting attempt to obtain general results in standard OLG model in a steady state situation see Willis (1988). By introducing an exogenous set of transfers he obtains the following result: these non-market transfers might either increase or decrease savings, boosting or offsetting the positive economic effects of population ageing. The net effect depends on the difference between the size of the transfers individuals will receive, and how much they will have to pay over the course of their remaining lifespan (Willis 1988).
} 
Table 1: Description of intergenerational transfers to the elderly and to the children and possibilities and reasons for government intervention

\begin{tabular}{|c|c|c|c|c|}
\hline $\begin{array}{l}\text { Transfers in Money and Time } \\
\text { in Household Production }\end{array}$ & Types & Private Motives & $\begin{array}{llll}\text { Substitution } & \text { by } & \text { Market } & \text { or } \\
\text { Government } & & & \end{array}$ & +/- Reason for Public Intervention \\
\hline To young dependents & $\begin{array}{l}\text { Birth } \\
\text { Subsistence } \\
\text { Health care } \\
\text { Personal care } \\
\text { Education } \\
\text { Bequests, Gifts }\end{array}$ & $\begin{array}{l}\text { Altruism (Forward) } \\
\text { Social Contract } \\
\text { Exchange }\end{array}$ & $\begin{array}{l}\text { Liquidity constraints prevent market } \\
\text { substitution } \\
\text { Personal care scarcely substitutable } \\
\text { Need to consider bargaining between } \\
\text { parents }\end{array}$ & $\begin{array}{l}\text { + Redistribution, equal opportunities and } \\
\text { intergenerational mobility } \\
+ \text { External positive effects on growth }\end{array}$ \\
\hline Old dependents & $\begin{array}{l}\text { Subsistence } \\
\text { Health care } \\
\text { Personal care } \\
\text { Gifts }\end{array}$ & $\begin{array}{l}\text { Altruism (Backward) } \\
\text { Social Contract } \\
\text { Exchange (Demonstration } \\
\text { effect) }\end{array}$ & $\begin{array}{l}\text { Personal care more substitutable than } \\
\text { for young }\end{array}$ & $\begin{array}{l}\text { + Redistribution } \\
+ \text { Myopia } \\
+ \text { Uninsurable risk (long-term care) } \\
\text { - External effect reducing fertility and } \\
\text { increasing old dependency rate }\end{array}$ \\
\hline \multicolumn{5}{|l|}{ Issues } \\
\hline Effects on capital accumulation & \multicolumn{4}{|c|}{$\begin{array}{l}\text { - PAYG financing might be explicit or implicit, helped by debt } \\
\text { - Capitalization also, so that it can occur explicitly through the capital market (capital accumulation) or implicitly through human } \\
\text { capital accumulation }\end{array}$} \\
\hline
\end{tabular}

Source: author's elaboration 
Nevertheless, even this simplified setting is quite illuminating for our analysis. In fact, the failure of the competitive economy to meet the optimal solution is closely related to the role of transfers in the economy. The fundamental reason is that the planner has the possibility to transfer resources among generations while this is not possible in the competitive economy.

Recall that different situations might arise when the competitive economy deviates from the optimal solution. The return of the market can either be higher (capital under accumulation), equal to (golden rule), or lower (capital over accumulation) than the return of the transfers system (the growth rate of population and productivity). In the latter case there is a possibility to derive a Pareto improvement by introducing a PAYG pensions system, but in the former case the optimal level of capital cannot be reached by funding through a Pareto improving transition (Diamond, 1965). Then, Samuelson's Serendipity Theorem shows that the only steady state of the competitive economy that might achieve the golden rule is the one in which the exogenous fertility rate is, by chance agents do not chose fertility in their analysis -, the one the planner would chose. Clearly Samuelson's (1975) framework is curious as it considers fertility as exogenous for the agent and endogenous for the planner. But it illustrates that optimality is highly related to the decisions taken in both production factors: capital and labour.

Considering the decentralized endogenous fertility solution seems to be more coherent. When the agents also decide fertility they take into account the marginal private benefit of having children and the marginal private cost of raising them. But they do not take into account the external effects they have on the economy due to their short-sighted time horizon - with non-altruism. In this situation the social marginal benefit - intergenerational transfer's effect - and cost - capital dilution effect - of having children are not considered. Among the policies that internalize these external effects, one uses a single instrument: introducing a pension system where the pension benefit is directly linked to own children contributions $^{11}$. Quite surprisingly, by means of this single instrument agents

\footnotetext{
${ }^{11}$ See Bental (1989) and Abío et al. (2004). In similar lines, Eckstein and Wolpin (1985) introduce a voluntary social security program that gives a return equal to the population growth rate,
} 
realize that they can save both in physical and human capital. Then, by arbitrage, the returns of both assets are equated and the (goldenest) golden rule is achieved.

More feasible policy alternatives protecting the pension rights of current pensioners have been proposed. For example, the Beveridgean pension system combined with a family allowance collecting the same amount of revenue (Schweizer, 1996). Nevertheless, note that these alternative policies are also exposed to demographic risk. On the contrary, there is a proposal by Sinn (2000), which considers a way to solve the transition: a partial transition to a mixed system combining a founded system for childless couples with a fertility-linked PAYG system for couples with children. This equilibrates the three burdens that should be borne along a demographic transition, holding the old PAYG system, capitalizing future pensions and raising children.

Overall, the discussion above shows the need to take into account the way the financing needs of the two sides of dependent life might be substituted by the market, the government and private institutions - mostly family - in order to determine to what extent the transfer system is balanced. A thorough theoretical analysis of this issue is far beyond the scope of this paper, being one of the main issues in the present-day research frontier. In order to shed some light on this issue, our aim is to employ the estimates that could be derived from NTA and GA indicators.

\section{NTA-GA methodologies and balance indicators}

\subsection{NTA and its relation to GA}

The National Transfer Accounts (NTA) method (Lee and Mason, 2004 and 2011) tries to disentangle how resources move among the different age groups through the different resource allocation devices available. In other words, it measures

although this system does not ensure a financial equilibrium out of the steady state. Peters (1995) investigates optimality in a model with endogenous growth. Schweizer (1996) establishes an isomorphism between the problem of optimal population growth in OLG models and the problem of determining optimal club size in local public goods models. Finally, Kolmar $(1997,2001)$

focuses on the effects of similar pension policies in an open economy. 
what is called age reallocation of resources, occurring either through the market asset-based reallocations - through government intervention -tax payment and transfers receipts - or through family transfers. In order to do so it translates all the System of National Accounts (SNA) aggregates in a given year into agespecific values as follows. Starting from the base year SNA identity, it is rearranged as shown in Equation [1],

$Y_{l}+Y_{a}+\tau_{g}^{+}+\tau_{f}^{+}=C+I+\tau_{g}^{-}+\tau_{f}^{-}$

where $Y$ stands for labour $(l)$ and asset $(a)$ income and $\tau$ stands for public $(g)$ or family $(f)$ transfer inflows (+) or outflows $(-), C$ is consumption and $I$ investment that equals savings $(S)$ below.

Rearranging [1] one can obtain,

$C-Y_{l}=Y_{a}-S+\tau_{g}^{+}-\tau_{g}^{-}+\tau_{f}^{+}-\tau_{f}^{-}$

for the whole economy, though it also holds for each age group, $e$,

$C(e)-Y_{l}(e)=Y_{a}(e)-S(e)+\tau_{g}^{+}(e)-\tau_{g}^{-}(e)+\tau_{f}^{+}(e)-\tau_{f}^{-}(e)$

The left hand side, called life cycle deficit ( $L C D)$, is the excess of resources consumed by each age group, which must be financed either by asset-based reallocations $(A B R)$-asset income minus savings- or by net public $\left(\tau_{g}^{+}-\tau_{g}^{-}\right)$or family $\left(\tau_{f}^{+}-\tau_{f}^{-}\right)$transfers, $T G$ or $T F$, respectively. Hence, we can also express it as,

or

$L C D(e)=A B R(e)+T G(e)+T F(e)$

as it holds both for the whole economy and for each age group.

NTA share some basic elements with generational accounting (GA), an applied method focused on measuring the effects of demographic changes on the sustainability of public finances (Auerbach et al. 1991, 1992, 1999). The standard GA evaluates, in a partial equilibrium setting, the extent to which the intertemporal budget constraint of the public sector holds, i.e. the outstanding 
initial debt in the base year will be covered by future net surpluses. Future surpluses are raised from net payments obtained from the estimated present and future generations. The estimation procedure starts from the aggregate net payments of living generations obtained imputing the base year budget aggregates by age and gender. The assumption of constant fiscal policy allows those payments to be maintained constant for future generations and hence the implicit debt/wealth - called sustainability gap - to be obtained as the intertemporal debt not covered by net payments of any generation.

Note that the main input of these calculations is very similar to the TG profile obtained in NTA. The method holds an age profile constant for all tax payments and transfer receipts. Then, in order to properly account for cohort effects, a constant productivity growth rate is applied to obtain the longitudinal profile for the subsequent cohorts.

Several sustainability indicators can be obtained. On the one hand, the total amount of the net present value of implicit wealth/debt - the sustainability gap can be expressed as a share of the base year GDP, or more interestingly, as a share of intertemporal GDP (the present value of future GDP). On the other hand, it can be expressed in generational terms. In practice, the sustainability gap is transformed into the difference in net payments made by present and future generations. In particular, the present value in the base year of net payments (net of transfers) made by a generation is obtained. This value expressed in per capita terms is called $\mathrm{GA}_{\mathrm{k}}-\mathrm{i}$. e. generational account of cohort born in year $k$. In principle the constant policy assumption would imply the same $G_{k}$ for all generations observed along their complete lifetime, except in what refers to income growth and discounting. Nevertheless, a counterfactual $\mathrm{GA}_{\mathrm{k}}$ for future generations is obtained by adjusting it to bring the current sustainability gap - if any- to zero. The comparison between GA for current and future newborns measures the generational imbalance.

Although GA and NTA come from different theoretical frameworks - Economics and Demography, respectively -, they coincide in analyzing the interaction between Economics and Demography, and end up sharing common features. 
Furthermore, their disparities, far from being an obstacle to combine them, lead to complementarities. Basically, both methods start from a given base year $t$, and analyze the interaction among some basic macroeconomic aggregates and the age structure of the population. In both cases the incidence of the aggregate is reflected in age profiles that are considered somehow constant. The main differences are as follows. First, while having the same basic structure, in GA the interest is to obtain long-term projections. This implies that it necessarily takes a forward-looking perspective by projecting the estimates obtained for the base year to the future. Second, both methods collect the information for public sector aggregates in the base year, while NTA applies the same imputation method to all the SNA aggregates and also to family transfers. Hence, both methods are complementary in some sense. By that means, NTA can complement the picture of the future given by GA. On the one hand, both methods might be helpful to derive backward looking and cohort analysis as long as data are available ${ }^{12}$. On the other hand, the cross-sectional estimates obtained in NTA can enrich the forward-looking estimates obtained in GA (Patxot et al. 2011b) ${ }^{13}$. In this sense it is worth mentioning that the main limits of the GA approach apply - in particular the failure to capture the general equilibrium changes in prices due to changes in the population structure. Indeed, these changes might be non-negligible although one of the most important - the change in the interest rate due to the foreseen change in capital intensity - might be reduced in an open economy.

\subsection{NTA balance indicators}

Clearly, NTA will allow for extensions of the set of sustainability indicators proposed in the GA literature, as shown in Section 4. Below we present an analysis of what can be drawn from NTA regarding balance of government

\footnotetext{
${ }^{12}$ In fact in GA it is usual to obtain life cycle indicators of the net payments of each cohort though these are all based on cross-sectional data. There are also some attempts to use NTA estimates both for backward and forward looking analysis. The former has been basically employed to compute the so-called first demographic dividend (Mason, 2007). The latter has been done to obtain a future prospective of different welfare state programs (Auerbach and Lee 2009, Patxot et al. 2011b).

${ }^{13}$ Another technical similarity is that both methods aim to obtain both flow and stock estimates. In fact GA estimates the implicit stock of debt by means of adding future net surpluses to the initial outstanding debt. NTA standard method has only established clear bases to estimate the flow account while it is aiming at estimating a stock account.
} 
intervention on both sides of dependent life. We start from a descriptive device proposed by Lee (1994b) -the arrow diagrams- and modify it to our purpose. From the empirical point of view, the author employs cross-sectional per capita age profiles, which could be considered as a precedent for the NTA profiles. From a theoretical point of view, it builds upon a quite simplified framework: a standard OLG model in a stable population steady state situation, adding detailed, forward and backward age specific transfers. This permits to express the demand for wealth along the life cycle $(W)$ in quite a stylized way, as:

$W=c \cdot\left(A_{c}-A_{Y_{l}}\right)$

Where $A_{c}$ and $A_{Y_{l}}$ are the average ages at which the average dollar is consumed and earned in the stable population and $c$ is the level of per capita consumption ${ }^{14}$. Note that by assuming a stable population steady state golden rule situation, longitudinal life cycle profiles can be extracted from the cross-sectional ones and it is possible to estimate real wealth by means of equation (6) and the NTA profiles of labour income and total consumption. Interestingly, Lee (1994b) illustrates this result using arrow diagrams. He shows, for each NTA concept (LCD, TG and TF), an arrow going from the average age of the outflow profile (or the financing source) to the average age of the inflow profile ${ }^{15}$. The average ages are obtained weighting the profiles by the population structure. And the width of the arrow is the per capita amount of inflow resources received weighted by the average labour income between 30 and 49 years old. Thus, the area of the arrow corresponds to the implied wealth, following Equation (6).

Furthermore, following the same reasoning, the amount of total wealth (W) can be split into real capital $(\mathrm{K})$ and transfer $(\mathrm{T})$ wealth by computing the average age of transfer recipients and payers, using, again, the corresponding NTA profiles. It is worth mentioning that the demand for wealth estimated this way would not correspond, in general, to the one observed in the real world. This would only be the case if the stylized steady state situation were true and the empirical age crosssectional profiles had no cohort effects at all. This situation is hardly conceivable

\footnotetext{
${ }^{14}$ By the golden rule assumption $\mathrm{Y}_{1}$ equals $\mathrm{C}$.

${ }^{15}$ Lee (1994b) does not mention NTA as such. But, as said above, it can be considered as one of the fundamental seminal references. The theoretical transfer framework was developed by Lee and his collaborators (Lee 1994a, Lee 1994b, Bommier and Lee 2003).
} 
but the estimation is interesting and can be useful for the main purpose of this paper, as seen below.

As we are especially interested in a synthetic and illustrative indicator of the resources movement to both dependent sides of the life cycle, we keep the arrow structure. Moreover, we want to measure the degree of intervention of the government on forward and backward (IFT). Therefore, we modify the Lee arrows in order to highlight how resources move from donors to both sides of dependent life. Hence, we apply the same equation (6), but we confront in the same arrow the average age of net donors and the average age of net recipients inside each profile (LCD, TG and TF).

\section{Results}

\subsection{Basic NTA results for Spain in 2000}

In Figure 1 the National Transfer Accounts age profiles obtained for Spain in 2000 are shown ${ }^{16}$. In particular, the four main per capita age profiles distinguished in Equation [5] are plotted. The life cycle deficit (LCD), together with the three possible ways of reallocating resources between age groups: public transfers (TG), private transfers (TF) and asset-based reallocations (ABR). The figure is quite illustrative. First, as expected, LCD is positive out of the central working age (from 26 to 58 in this case); that is, individual consumption exceeds labour income for those ages, while it is negative during working age. Second, as a consequence of their economic dependence, the young and the elderly receive net transfers from the government $-\mathrm{TG}$ is positive - while they contribute - TG becomes negative - during the productive ages. Note that the cutting ages for LCD and TG are not exactly the same - TG is negative from 24 to 60 . This is due to the role of the other age reallocation devices, i.e. asset-based reallocations and private transfers.

\footnotetext{
${ }^{16}$ For a first approximation to these estimates, see the chapter devoted to Spain in Lee, R. and A. Mason, eds. (2011), Patxot et al., (2011a). For a more detailed account on estimation methods and data sources see Patxot et al. (2010).
} 
If one considers strictly life cycle savings, omitting bequests, the natural age shape of $\mathrm{ABR}$ is zero until age 15, as there are no assets, or asset income. Later, as individuals can enter the labour market and start saving, ABR becomes negative and stays so, as long as savings exceed asset income. ABR becomes nil if all asset income is saved and starts being positive when saving is overcome by asset income. The absence of a negative initial ABR can be due either to a bequest received that generates $Y_{a}$ higher than $S$ or to the fact that adults become indebted to finance their consumption or transfers to their children. Intergenerational transfers can interact in many more ways as, together with bequests, inter vivos transfers from grandparents to children or grandchildren, or from children to parents can occur. For Spain, only from age 35, ABR is clearly positive and it is especially high from age 65 . This could contribute to the positive transfers of elderly shown in the TF profile.

Figure 1. Per capita National Transfer Accounts, Spain (2000)

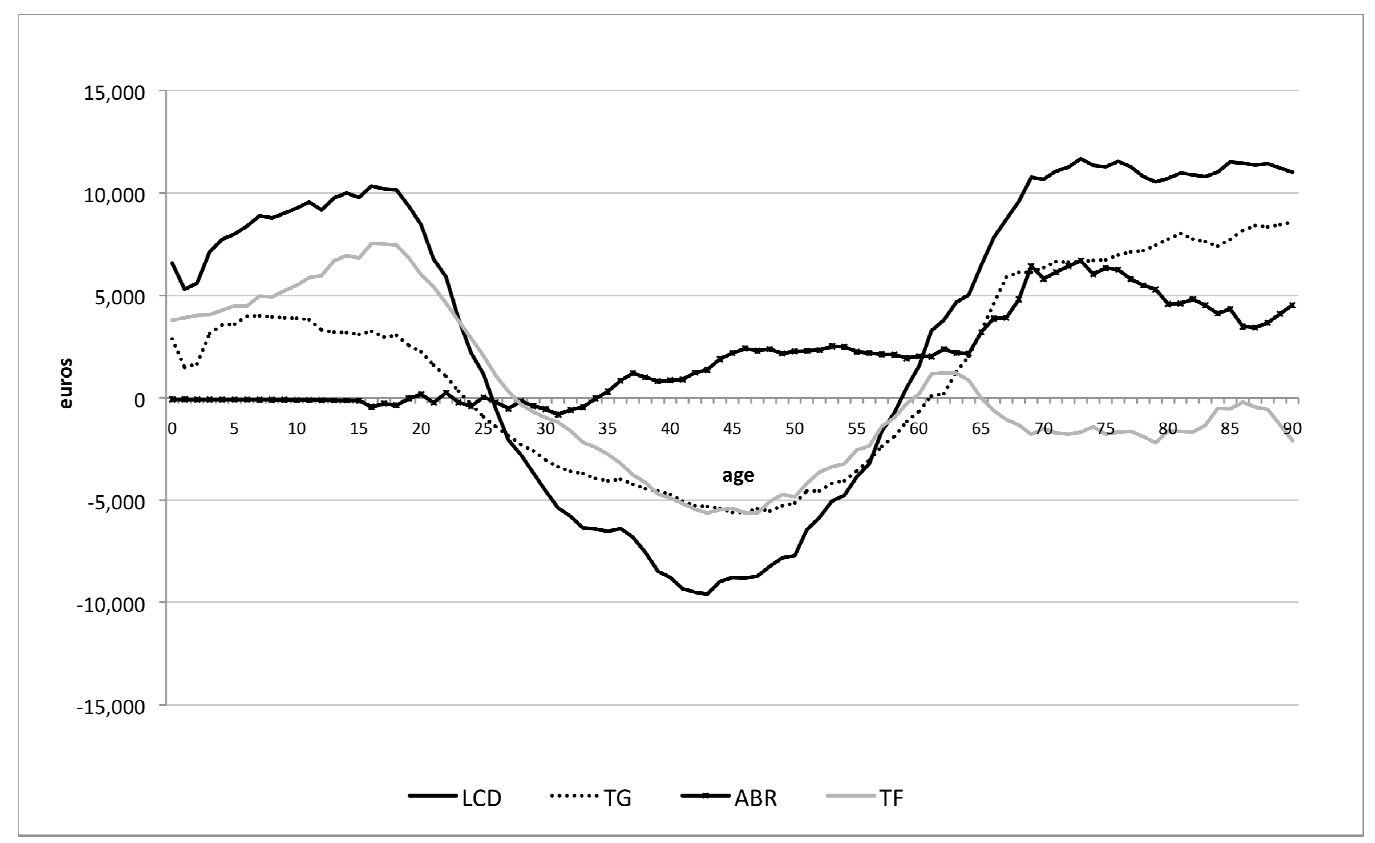

Source: Authors elaboration

Interestingly, the net transfers profile (TG), which is, together with future population projections, the main input for GA calculations, illustrates to some extent the degree of intervention of the government on forward and backward intergenerational family transfers. From this, it is clear that the size is higher for the elderly than for the young. Nevertheless, one can obtain more informative 
estimates by combining some of the other NTA age profiles. To summarize this information, a synthetic indicator can be obtained by adding up the subsequent aggregated areas in Figure 1. This indicator would represent the share of LCD financed by means of each reallocation device and is shown as a single point in a triangle diagram as in Figure 2. Each side of the triangle is the share of LCD financed by each of the available financing sources (Family transfers, Public transfers and Asset-Based reallocations). The shares must add up to 100 by definition, but they need not all be positive. On the one hand, each of the three vertices of the triangle represents exclusive reliance on one of the three funding sources, with the other two being zero. Any movement toward one of these vertices represents an increase in the share of that source. Along the sides of the triangle, one source is zero while the other two vary. On the other hand, the gridlines indicate the points at which the corresponding financing source is constant at 1,2 or 3 quarters. Movement along one of the gridlines implies that one source is constant while the other two vary. Points lying outside the triangle indicate that one or more of the components are negative.

Figure 2 shows the situation for the young (0-14) and the old (65+) in Spain. In the case of the young one can see that LCD financing relies mainly on family transfers $(61 \%)$ while there are almost no asset-based reallocations. The latter is in fact a small negative value $(-1.2 \%)$. On the contrary, in the case of the elderly LCD is mostly financed by public transfers (63\%), while family transfers are negative $(-13.2 \%)$, which means that they are actually net donors of private transfers to the other age groups. 
Figure 2. Components of Children and Old-Age Life Cycle Deficit

Source: Authors elaboration based on www.ntaccounts.org methodology

\subsection{Measuring the government intervention in Intergenerational Family Transfers}

\subsubsection{Balance indicators in the GA tradition}

Below, a reference to what the GA perspective can offer to the issue we are tackling is derived. As said above the comparison of $\mathrm{GA}_{\mathrm{k}}$ for different cohorts allows a measurement of the intergenerational redistribution of resources due to current debt and future demographic changes. In particular, the main GA sustainability indicators for each social program, splitting those aimed at the young and at the elderly, are computed, following Patxot and Farré (2007). In other words, the size of the expenditure effort aimed at each side of the dependent period is measured, as suggested by the abovementioned Schweizer (1996) policy proposal.

Table 2 summarizes the results obtained using the TG profile shown above. The first rows of the Table show the value of the primary surplus for the total budget in 2004 and 2050 together with the sustainability gap. As explained in Section 3, the sustainability gap figure $(2.02 \%)$ tells us that in order to cover the sustainability gap hidden by the current fiscal policy it would be necessary to collect $2.02 \%$ of annual GDP on average. It is worth noting that this average value is far below the value of the initial primary surplus $(+1.91 \%)$ but far above the value of the primary surplus in the worst year of the projection, $2050(-7.48 \%)$, showing the sensitivity of the public budget to population age structure. If we decompose these figures in the different social programs taking into account those aimed at the elderly and at the young we obtain the values given in the following rows in Table 2. The first column shows the $\mathrm{GA}_{\mathrm{k}}$ for each social program, while 
the last two columns show the expenditure to GDP ratio in the base year and in the worst year of the projection.

Table 2: Degree of intervention of the government in Intergenerational Family Transfers (IFT)

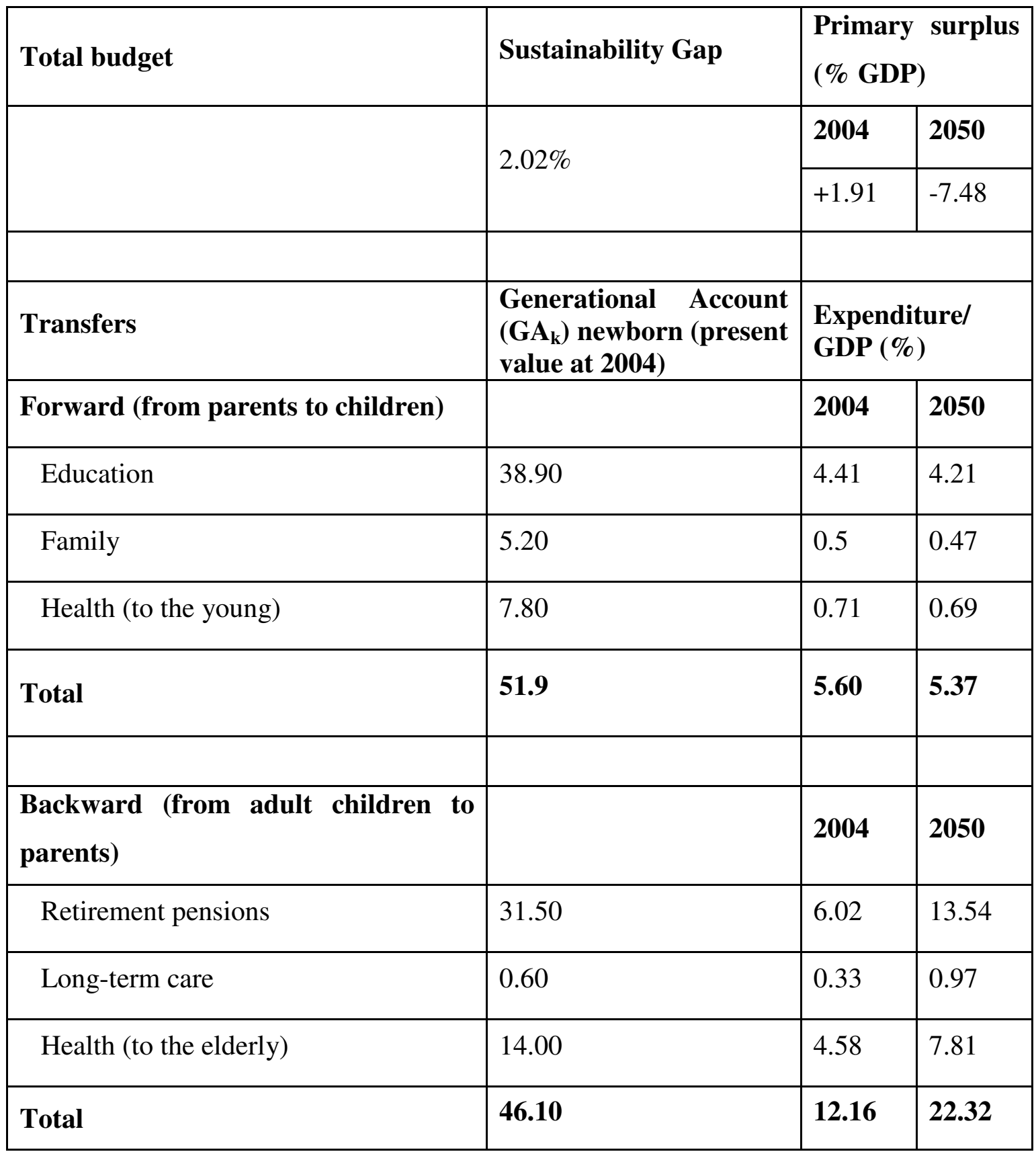

Source: Authors' elaboration.

At first, looking at the value of the $\mathrm{GA}_{\mathrm{k}}$ in the first column, the government intervention on transfers to children (51.9) seems higher than the one aimed at elderly parents (46.1). Nevertheless, we should bear in mind that this indicator is highly influenced by discounting. Note that, as is usually done in GA, by 
assuming a dynamic efficiency situation - the interest rate exceeds the growth rate of the economy - the sum of the present value of monetary flows tends to zero. This also implies that payments received during the first years in life - child care are by far more valued than those received later in life -pensions. Hence, one should look at other indicators to complete this picture. The last two columns give the ratio of total expenditure to GDP in each program in two particular years. The first is near the base year 2004, in which Spain turns out to enjoy one of the lowest total dependency rates of the past and future century (49\%). On the contrary, in year 2050 the Spanish population reaches the worst total dependency rate along the period $(90 \%)$. The total expenditure on the elderly doubles that aimed at the young in the base year (12.16\% compared to $5.60 \%)$, while the ratio is 1 to 4 in 2050 (22.32\% compared to $5.37 \%$ ). This figure is quite illustrative, but by using the four NTA profiles one can complete this picture by comparing public transfers to other financing sources.

\subsubsection{Balance indicators using NTA profiles}

In this section we aim to use NTA estimates to measure the degree of intervention on forward and backward intergenerational family and government transfers, using an extension of the arrow diagrams proposed by Lee (1994b). As said in Section 3.2, these indicators are similar to those derived from NTA methodology, but they add, in a simple way, the dimension of direction.

Figure 3 shows the basic arrows extracted from Lee (1994b). Panel a) shows the arrows corresponding to the main NTA profiles -LCD, net TG and net TF- for the Spanish case, while Panel b) compares Spanish LCD with the one obtained for other countries.

Figure 3: The Lee Arrows

Panel a. The Spanish case, 2000 for LCD, TG and TF 


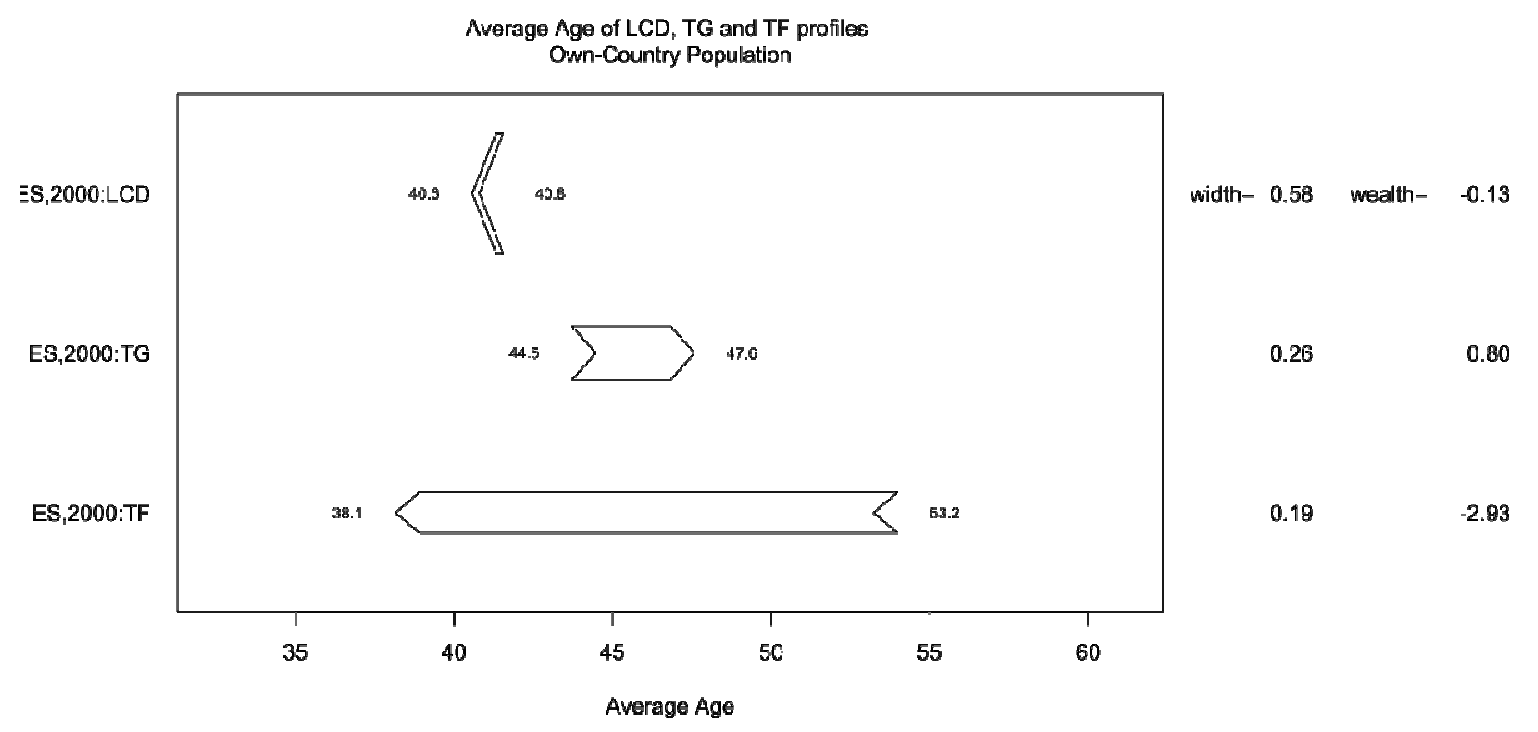

The point of the arrow is the avg age of $\mathrm{C}, \mathrm{TGI}$, and $\mathrm{TFI}_{i}$ the tail of $\mathrm{YL}_{1}-{ }^{-} \mathrm{GO}$ and $\mathrm{TFO}$.

Width is avg of per capita LCD, avg of per capita TG and avg of per capita TF relative to avg YL(30-9). Source:

Authors calculation.

Panel b. LCD Lee arrows for selected countries.

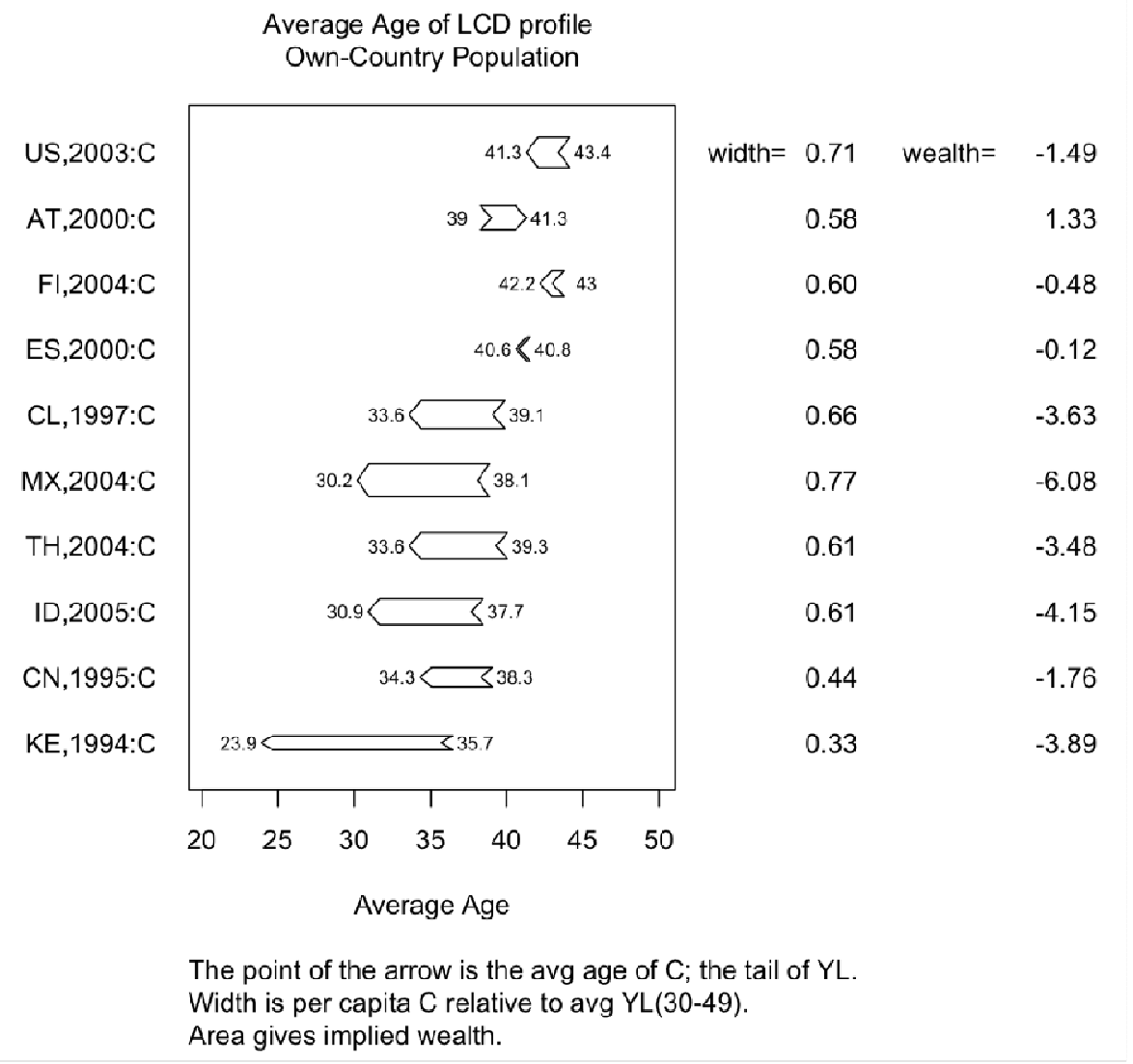

Source: Authors calculation for Spain and www.ntaccounts.org for other countries.

In the case of Spanish LCD, the average age of consumers (inflow profile), 40.6 years-old, is very closed to the average age of producers (outflow profile), 40.8 
years-old, although the width, 0.58 is quite important compared to TG and TF arrows. However, compared to other countries, we see big differences. For those European countries and the US, we can observe small arrows. These arrows are larger, in width and in average age differences, for countries from Latin America, Asia and Africa, which means that both the implied wealth transferred from producers to consumers is greater and the average age difference between them is higher. It is worth noting that except Austria (AT), all countries have a downward direction on consumption arrow, confirming that the average age of producers is still higher than the average age of consumers. This situation tends to change with population ageing and explaining why the difference between these two ages is smaller in more aged countries.

Once the direction of LCD (producers to consumers) is seen, in Figure 3 arrows for private and public transfers are shown. In the case of government or public transfers, resources go from 44.5 years old to 47.6 years old on average, with a smaller width than the one of LCD, only 0.26 . As expected, family transfers go in the opposite direction, and the average age of outflow, 53.2 years old, is older than the average age of recipients, 38.1 years old. Finally, the implied wealth transferred in private intergenerational transfers is greater than that transferred in public transfers.

\section{The modified Lee Arrows}

As explained in Section 3.2, we modify the Lee arrow diagrams to measure the degree of intervention of the government on forward and backward intergenerational transfers (IFT). Each profile (LCD, TG and TF) is divided into several arrows, where each one goes from the average age of donors to the average age of recipients. For the LCD, for example, we aim to highlight the fact that some workers (negative part of LCD) direct their surplus resources towards both sides of dependent life, to the elderly and to the young (positive part of the LCD). This shows the generational distribution of resources, i. e. the extent to which the surplus of the productive generation is directed to finance both sides of the dependent life. The arrows then go from the average surplus producer to the 
average receivers (old and young). And the total (negative) life cycle deficit (LCD) - life cycle surplus - is considered as the outflow of both inflows.

The resulting arrows are shown in Figure 4. There is an age group of donors around 40 years old in each profile (41.3 for LCD, 41.7 for TG and 43.4 for TF). Resources go from these age groups to the young and to the old. Nevertheless, in the case of private transfers, a particularity of the Spanish transfer system arises with the existence of another group of donors among the elderly, with an average age of 74.9 years old. This reflects the fact that the elderly give transfers back to their offspring. Recipients -or age groups with a net deficit profile- are divided into two groups, children and the elderly. Their average ages differ slightly for children, where they are 13.1 years old in the LCD, 11.5 years old in TG and 14.3 years old in TF. The average age of the elderly is 73.7 years old in the LCD profile and 75 years old in TG profile, a very different age than the 62.3 years old of the elderly receivers group of TF, partly because of the existence of an elderly surplus group in this profile.

In contrast with Figure 3 where resources move in one direction, Figure 4 highlights the fact that these move in both directions, giving richer information. Look, first, at the arrow referring to LCD in Figures 3 and 4. In the latter the width of the arrows indicates that consumption per capita of the children group is slightly lower than consumption of the elderly. Nevertheless, there is a slight difference in the age gap (38.2 and 31.4 to the young and to the old, respectively) that goes in the opposite direction. The result is a short "aggregate" LCD arrow going from the young to the old. In other words, the implicit wealth of the elderly is higher than the one for children. Something similar happens if one looks at TG and TF arrows. Regarding TG the longer (33.3 years versus 30.2$)$ and higher (0.52 versus 0.23 ) transfers to the old (Figure 4) imply that the net or aggregate transfer goes from the young to the old in Figure 3. The decomposition of TF is also quite illustrative as mentioned above.

In relation to TG and TF modified arrows, it is also important to note that the elderly group receives a per capita transfer amount much greater from public transfers than from private transfers. Contrary to that, children receive, on 
average, private and public transfers per capita that are similar (width), although a little bit higher from private transfers, as transfers from the middle age group and from the elderly group have to be added up ${ }^{17}$. Therefore, at least during 2000, in Spain, the intervention of the government on the IFT seemed to be greater among transfers to the elderly. In fact, one could say that the existence of an elderly group of private transfer donors could compensate for the relatively higher generosity of the government with the elderly compared with children. The extent to which this is reflecting a cohort effect would require further investigations based on past and future evolution of transfers.

\footnotetext{
${ }^{17}$ In order to estimate the per capita transfer inflow in private transfers, with two age groups of donors, we divided the amount transferred proportionally to the amount of outflow in each age group (the middle age group and the elderly age group). Therefore, as the amount transferred from the elderly is lower than the one from the middle group, the TF arrows' width from the 74.9 years old group are thinner.
} 
Figure 4. Modified Lee Arrows applied to LCD, TG and TF by deficit and surplus age groups, Spain 2000.

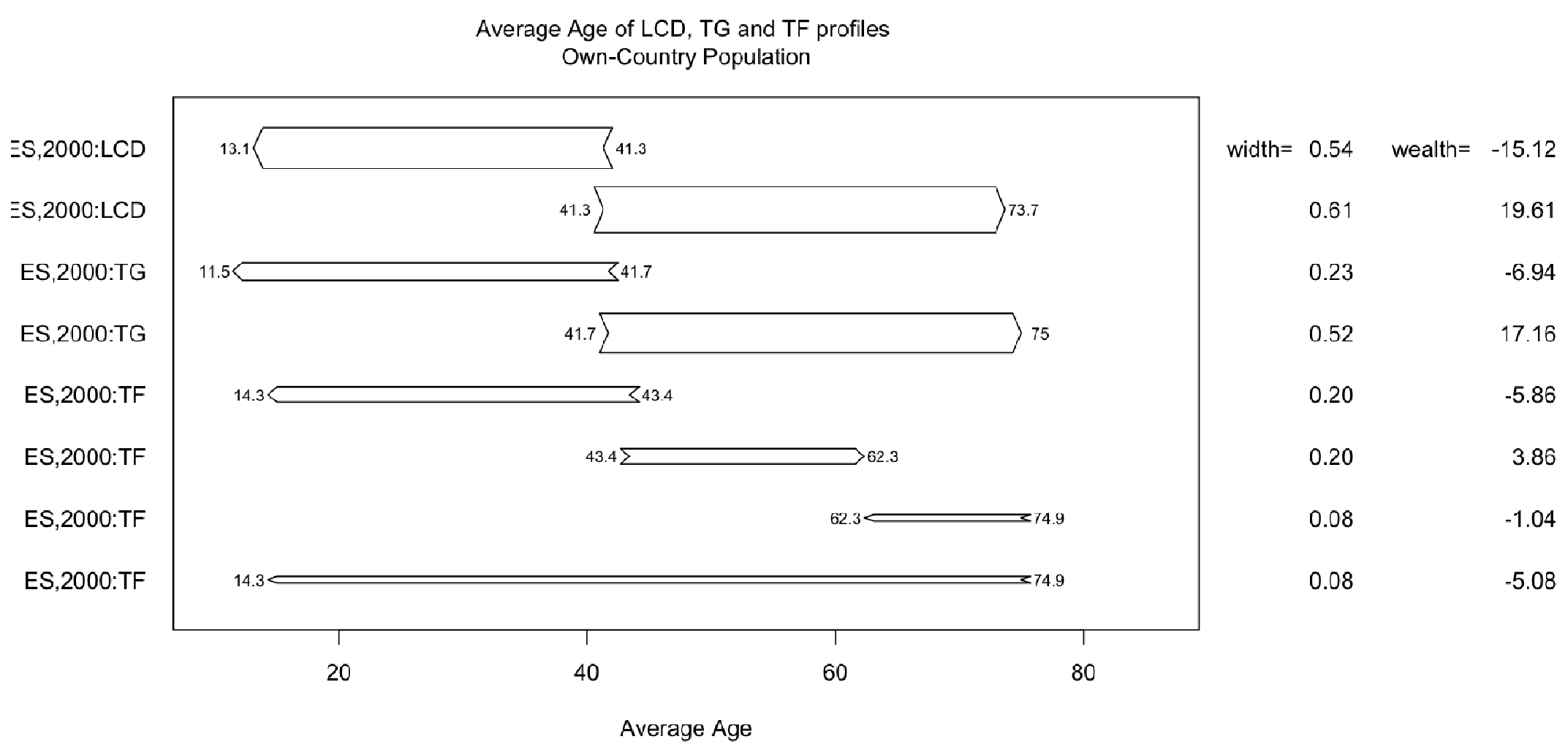

The point of the arrow is the avg age of LCD, TG, and TF donors; the tail of LCD, TG and TF receivers. Width is per capita C, TGI and TFI relative to avg YL(30-49).

Area gives implied wealth. 


\section{Concluding remarks}

Ideally, the overall impact of ageing on the Economy - including the sustainability of the welfare state - should be evaluated taking into account the government intervention in both forward and backward family transfers. One could say that the fundamental issue is the extent to which this intervention toward both sides of the life cycle is balanced. It is worth considering that the asymmetry between the two dependent periods in life does not necessarily recommend a direct balancing criterion. On the contrary, the fact that the needs at the end of life are in general more substitutable by the market seems to recommend orienting public transfers to the young. There are also efficiency reasons for this to the extent that education is one of the main driving forces of endogenous growth and that many of the benefits are external to individual decisions. In fact, in a perfectly competitive and complete market world, the reasons to intervene in transfers to the elderly would be merely intragenerational income redistribution, while other examples of redistribution are often forgotten. Interestingly, the fact that everybody has a positive probability of reaching elderly life and becoming a transfer receiver, while not everybody has children, gives rise to an issue which has been almost unexplored in the redistribution literature: those who have children bear most of the cost of raising future tax payers while all their cohort companions benefit from it. This calls for a separation of redistribution policy and the intervention in intergenerational transfers.

This paper contributes to the empirical side of this issue that remains unanswered in the theoretical literature. After discussing the extent to which generational accounting (GA) indicators might be helpful, indicators based on NTA crosssectional estimates, together with an extension of Lee (1994) Arrow diagrams, are developed in order to obtain a measure of the balance of government intervention on forward and backward family transfers. First, the share of life cycle surplus aimed at each side of dependent life is shown in an arrow going from average age of those giving a surplus to average age of those having a deficit. Second, the way labour income supports public and private transfers is characterized by building an arrow from the average age of workers to the average age of transfer receivers. 
Our results show that in the case of Spain the degree of government intervention on transfers to the elderly (backward intergenerational family transfers) is higher than its intervention on transfers to the children. This might be one of the reasons why the Spanish fertility rate reached one of the lowest values in the world and is recovering so slowly.

Further research is needed along different lines. From the empirical perspective the increasing availability of longitudinal information will help to control for the presence of cohort effects on the micro profiles and check for the robustness of the results. In the meanwhile, international comparisons might provide useful insights for the necessary extension of the theoretical analysis on intergenerational transfers, so that thorough conclusions on the effects of a particular configuration of the transfer system on capital accumulation might be extracted. Indeed, the way public and private transfers can complement each other and capital accumulation for financing human needs along the life cycle is crucial to understand growth.

Clearly, the indicators proposed and the age profiles from which these are derived can give way to policy conclusions. The NTA estimates provide a precious basis for this. Given their transparency, these indicators can be obtained and compared in international terms. Hence, they could contribute to fill the need for comparable indicators recently raised by the so-called Stiglitz commission.

\section{References}

Abío, G., Berenguer, E., Bonin, H., J. Gil, J. \& Patxot, C. (2003). Is the Deficit under Control? A Generational Accounting Perspective on Fiscal Policy and Labour Market Trends in Spain. Investigaciones Económicas 27(2): 309-341.

Abío, G., Mahieu, G. \& Patxot, C. (2004). On the Optimality of PAYG Pension Systems in an Endogenous Fertility Setting. Journal of Pension Economics and Finance, 3 (1): 35-62.

Auerbach, A. \& Kotlikoff, L. (1987). Dynamic Fiscal Policy. Cambridge: Cambridge University Press.

Auerbach, A. \& Lee, R. (2009). Welfare and Generational Equity in Sustainable Unfunded Pension Systems. NBER working paper, w14682, January. 
Auerbach, A. \& Oreopoulos, P. (2000). The Fiscal Effects of U.S. Immigration: A Generational Accounting Perspective. Tax Policy and the Economy, 14: 123-156.

Auerbach, A. J. (1997). Quantifying the current U.S. fiscal imbalance. National Tax Journal, 50: 387-398.

Auerbach, A., \& Kotlikoff, L. (1999). The Methodology of Generational Accounting. In A. Auerbach, L. Kotlikoff, and W. Leibfritz (Eds.). Generational Accounting around the World (pp. 31-41). Chicago: University of Chicago Press.

Auerbach, A., Gokhale, J. \& Kotlikoff, L. (1991). Generational Accounting: A Meaningful Alternative to Deficit Accounting. Tax Policy and the Economy 5: 55-110.

Auerbach, A., Gokhale, J. \& Kotlikoff, L. (1992). Generational Accounting: a New Approach to Understanding the Effects of Fiscal Policy. Scandinavian Journal of Economics 94: 303-318.

Auerbach, A., Gokhale, J. \& Kotlikoff, L. (1994). Generational Accounting: A Meaningful Way to Evaluate Fiscal Policy. Journal of Economic Perspectives 8(4): 73-94.

Auerbach, A., Gokhale, J. \& Kotlikoff, L. (1995). Restoring Generational Balance in US Fiscal Policy: What will it Take? Federal Reserve Bank Cleveland Economic Review, 31: 2-12.

Auerbach, A., Gokhale, J., Kotlikoff, L. \& Steigum, E. (1993). Generational Accounting in Norway: Is Norway Overconsuming its Petroleum Wealth. Working Paper of the Federal Reserve Bank of Cleveland, 93-05.

Auerbach, A., Kotlikoff, L. \& Leibfritz, W. (1999). Generational Accounting around the World. Chicago: University of Chicago Press.

Becker, G., Murphy, K. \& Tamura, R. (1990). Human Capital, Fertility, and Economic Growth. Journal of Political Economy, 98: S12-S37.

Bental, B. (1989). The Old Age Security Hypothesis and Optimal Population Growth. Journal of Population Economics, 1 (4): 285-301.

Boll, S., Raffelhüschen, B. \& Walliser, J. (1994). Social Security and Intergenerational Redistribution: A Generational Accounting Perspective. Public Choice 81: 79-100.

Bommier, A. \& Lee, R. (2003). Overlapping Generations Models with Realistic Demography. Journal of Population Economics, 16: 135-160. 
Bonin, H. (2001). Generational accounting: theory and application. Berlin: Springer Verlag.

Bonin, H. \& Patxot, C. (2005). La Contabilidad Generacional como una herramienta de análisis de la sostenibilidad fiscal: panorama de la metodología. In E. Berenguer et al. (Eds.). Contabilidad Generacional en España, Estudios de Hacienda Pública, Instituto de Estudios Fiscales.

Bonin, H., Gil, J. \& Patxot, C. (2001). Beyond the Toledo Agreement: the intergenerational impact of Spanish pension reform. Spanish Economic Review 3: 111-130.

Börstinghaus, V. \& Hirte, G. (2001). Generational accounting versus computable general equilibrium. Finanz Archiv 58 (3): 227-243.

Bovenberg, A. \& ter Rele, H. (1999). Government Finance and Ageing in the Netherlands. In European Commission (Ed.). Generational Accounting in Europe (pp. 133-147). European Economy. Brussels: European Communities.

Cigno, A (1993). Intergenerational Transfers Without Altruism. European Journal of Political Economy, 9: 505-518.

Cigno, A. \& Luporini, A. (2006). Optimal policy towards families with different amounts of social capital, in the presence of asymmetric information and stochastic fertility. CESifo Working Paper, 1664:1-28.

Costa, J. \& Patxot, C. (2004). The intergenerational impact of long-term care financing alternatives in Spain. Geneva Papers on Risk and Insurance Theory, Issues and practice, 29 (4): 599-619.

Crèmer, H., Gahvari, F., \& Pestieau, P. (2006). Pensions with Endogenous and Stochastic Fertility, Journal of Public Economics 90:2303-2321.

Diamond, P. (1965). National Debt in a Neoclassical Growth Model. American Economic Review, 55: 1126-1150.

Diamond, P. A. (1994). Generational accounts and generational balance: an assessment. National Tax Journal, 49: 597-607.

Eckstein, Z. \& Wolpin, K. I. (1985). Endogenous fertility and optimal population size. Journal of Public Economics, 27: 93-106. 
European Commission (1999). Generational Accounting in Europe. European Economy, Reports and Studies, 6. Brussels: European Communities.

Fehr, H. \& Kotlikoff, L. (1996). Generational accounting in general equilibrium. FinanzArchiv 53: $1-27$.

Galor, O. \& Weil, D. (2000). Population, Technology and Growth from the Mathusian Regime to the Demographic Transition. American Economic Review, 90: 806-828.

Jimeno, J.F., Rojas, J. \& Puente, S. (2008). Modelling the Impact of Aging on Social Security Expenditures. Economic Modelling, 25(2): 201-224.

Kolmar, M. (1997). Intergenerational redistribution in a small open economy with endogenous fertility. Journal of Population Economics, 10: 161-183.

Kolmar, M. (2001). Optimal intergenerational redistribution in a two-country model with endogenous fertility. Public Choice, 106: 23-51.

Lee, R. D. (1994a). The Formal Demography of Population Aging, Transfers, and the Economic Life Cycle. In L. G. Martin and S. H. Preston (Eds.) Demography of Aging (pp.8-49). Washington, D.C.: National Academy Press.

Lee, R. D. (1994b). Population, Age Structure, Intergenerational Transfers, and Wealth: A New Approach, with Applications to the US. Journal of Human Resources, 29 (4): 1027-1063.

Lee, R. \& Mason, A. (2004). Macroeconomic Demography of Intergenerational Transfers. National Transfer Accounts Working $\quad$ Paper 1. http://www.ntaccounts.org/doc/repository/LM2004.pdf.

Lee, R. \& Mason, A. (2011). Population Aging and the Generational Economy: A Global Perspective. Cheltenham, UK: Edward Elgar.

Lee, R., Mason, A. \& Miller, T. (2003). Saving, Wealth, and the Transition from Transfers to Individual Responsibility: the cases of Taiwan, and the United States. The Scandinavian Journal of Economics, 105: 339-357.

Mason, A. (2007). Demographic Dividends: The Past, the Present, and the Future. In M. Yamaguchi (Ed.). Population Change, Labor Markets and Sustainable Growth: Towards a New Economic Paradigm (pp.75-98). Contributions to Economic Analysis, v. 281. Bingley, UK: Emerald Group Publishing Limited. 
Mason, A. \& Lee, R. (2011). Introducing Age into National Accounts. In R. Lee \& A. Mason (Eds.). Population Aging and the Generational Economy: A Global Perspective. Cheltenham, UK: Edward Elgar.

Patxot, C. \& Farré, R. (2007). Evaluación de la sostenibilidad del estado del bienestar en España. Madrid: Ediciones 2010.

Patxot, C., E. Rentería, M. Romero and G. Souto (2010), How intergenerational transfers finance lifecycle deficit in Spain, NTA Working Paper Series, No. 10- 04, available at http://www.ntaccounts.org, accessed 24 September 2010.

Patxot, C., Rentería, E. Sanchez-Romero, M., Souto, G. (2011a). How intergenerational transfers finance the lifecycle deficit in Spain. In R. Lee \& A. Mason (Eds.). Population Aging and the Generational Economy: A Global Perspective. Cheltenham, UK: Edward Elgar.

Patxot, C., Rentería, E. Sánchez-Romero, M., Souto, G. (2011b). Integrated results for GA and NTA for Spain: some implications for the sustainability of welfare state. Moneda y Crédito, 231: 7-51.

Peters, W. (1995). Public Pensions, Family Allowances and Endogenous Demographic Change. Journal of Population Economics, 8: 161-183.

Rangel, A. (2003). Forward and Backward Intergenerational Goods: Why Is Social Security Good for the Environment? The American Economic Review, 93 (3): 813-834.

Samuelson, P. A. (1975): The Optimum Growth Rate for Population, International Economic Review 16, pp. 531-538.

Schweizer, U. (1996). Endogenous fertility and the Henry George Theorem. Journal of Public Economics, 61: 209-228.

Sinn, H.-W. (2000). Why a Funded System is Useful and Why it is not Useful. International Tax and Public Finance, 7: 389-410.

Sinn, H.-W. (2004). The pay-as-you-go pension system as fertility insurance and an enforcement device. Journal of Public Economics, 88(7-8): 1335-1357.

Wigger, B. U. (1999). Pay-As-You-Go Financed Public Pensions in a Model of Endogenous Growth and Fertility. Journal of Population Economics, 12: 625-640. 
Willis, R.J. (1988). Life Cycles Institutions Population Growth: A theory of the Equilibrium Interest Rate in an Overlapping-Generations Model. In R.D. Lee, W.B. Arthur \& G. Rodgers (Eds). Economics of Changing Age Distributions in Developed Countries (pp. 106-138). Oxford: Oxford University Press.

Zhang, J. \& Nishimura, K. (1993). Old-age Security Hypothesis Reconsidered. Journal of Development Economics 41: 191-202. 